\title{
Sex and perceptions of dependency in a helping situation
}

\author{
L. P. McGOVERN and JAN L. DITZIAN \\ State University of New York, College at Buffalo, Buffalo, New York 14222 \\ and \\ STUART P. TAYLOR \\ Kent State University, Kent, Ohio 44242
}

\begin{abstract}
Male subjects were placed in a situation where they could help by diverting electric shock to themselves which could go to a confederate. Subjects helped female confederates significantly more often than male. Ratings by the subjects of the confederates seemed to follow cultural role prescriptions. They rated females as significantly weaker and more dependent. They rated males as more competitive, aggressive, and braver than females.
\end{abstract}

The results of studies in which the effects of sex and dependency on helping have been examined suggest an interaction of the variables. Schopler and Bateson (1965), for example, reported that females helped a highly dependent female more than a less dependent female, while the reverse was true for males. Same sex dyads were used in this study. Therefore, as Gruder and Cook (1971) note, "It is not clear whether the sexes differ in their willingness to help dependent persons or whether both sexes have learned to help females more when they are dependent than nondependent and to help males more when they are nondependent than when they are dependent." Gruder and Cook attribute the effect to the sex of the recipient of aid. In a study in which both the sex of the potential helper and the sex of the dependent person were varied (1971), they found no effect of the sex of the helper. They report that dependency made no difference in help given to males, but that females who were dependent received significantly more help than females who were not dependent.

Perhaps the most interesting finding of these studies is that high dependency in a male apparently does not elicit higher levels of helping and in fact may elicit lower levels. Such behavior seems antinormative. As Berkowitz and Daniels (1964) point out, there is "a cultural norm prescribing that the individual should help those who are dependent upon him." Schopler and Bateson (1966) attempt to deal with the apparent contradiction by offering the explanation that the potential male benefactor views the situation competitively. They argue that "Men tend to be oriented toward a struggle with their physical and social environment. They, therefore, tend to be competitive and highly conscious of their

This paper is sponsored by F. Robert Treichler, who takes full editorial responsibility for it, own standing relative to others in the struggle for survival." Thus, they would be less willing to help a fellow male. However, as was noted, Gruder and Cook (1971) found that the difference in helping levels was attributable to the sex of the beneficiary and not the sex of the helper. Apparently, dependency in the male is perceived differently than dependency in the female. Gruder and Cook suggest that "males in the United States are supposed to be independent and competent (therefore dependency) may be perceived as acting out of role."

In neither of the studies examined, nor in other studies, has there been an attempt to check the subjects' perceptions of the beneficiary. The present study was designed to test these perceptions. Subjects participated with a confederate in a situation in which electric shock could go to either of them unless one of them volunteered to take the shock. Dependency was established through the behavior of the confederate, who jerked his/her arm and vocalized "Ow!" at the ostensible receipt of shock, indicating that he/she needed help. The experiment was presented to subjects as a study of physiological responding in a stressful, decision-making situation. Helping was defined by the subject's volunteering to take the shock. Since the Gruder and Cook (1971) study indicated that the sex of the benefactor was not crucial, male students only were used with male and female confederates. At the conclusion of the experimental task, subjects completed questionnaires in which they rated their anxiety and the unpleasantness of the shock they and the confederate received. They also rated the confederate and themselves on 29 adjective pairs including dependenceindependence. It was thought that these ratings could provide some insight into the differential behavioral reactions to dependency in the two sexes. 
Table 1

Mean Ratings of Confederate on Adjective Pairs

\begin{tabular}{llc}
\hline & \multicolumn{2}{c}{ Sex of Confederate } \\
\cline { 2 - 3 } Adjective Pair & Male & Female \\
\hline $0-5$ & & \\
Weak-Strong & 1.45 & $.85^{*}$ \\
Brave-Cowardly & 2.95 & $3.25^{*}$ \\
Leader-Follower & 3.25 & $3.75^{* *}$ \\
Dominant-Submissive & 3.50 & 4.00 \\
Attractive-Ugly & 2.50 & $1.25^{* *}$ \\
Bad-Good & 3.15 & $4.05^{* *}$ \\
Masculine-Feminine & 1.45 & $4.75^{* *}$ \\
Competitive-Noncompetitive & 2.70 & $3.80^{*}$ \\
Happy-Sad & 2.35 & $3.30^{*}$ \\
Honest-Deceitful & 1.30 & $.80^{*}$ \\
Aggressive-Nonaggressive & 3.45 & $4.20^{*}$ \\
Independent-Dependent & 2.70 & $3.50^{* *}$ \\
Small-Large & 2.50 & 1.50 \\
\hline
\end{tabular}

${ }^{*} p<.05 \quad{ }^{* *} p<.01$

\section{METHOD}

\section{Subjects and Design}

The subjects were 40 male undergraduates enrolled in an introductory psychology course at Kent State University. The sex of the confederate and shock level was varied. Shock was varied between full and one-half threshold levels between the first and second series of trials, counterbalanced for order.

\section{Procedure}

The subjects and confederate were seated side by side at matching one-arm desks, each with a signal box before him/her. Shock electrodes and dummy physiological recording electrodes were strapped to their arms. Following the determination of shock thresholds for the confederate and subject, a tape recording of the task instructions was played.

The instructions stressed physiological measurement. These included the statements:

We are interested in whether or not accepting an electric shock or watching another person take an electric shock leads to physiological arousal.

There are two conditions in this experiment, the both condition and the one condition. On the box in front of you are two colored lights and a red button. One light is labeled the both light; the other is labeled the one light. When the both light lights up, it means that both subjects are scheduled to receive an electric shock. When the one light lights up, shock is delivered to the subject who presses the red button within $10 \mathrm{sec}$. If no one presses the red button within this period, the shock will go to only one subject. The subject that will receive the shock is determined in a random manner.

For a "both" trial the appropriate signal light came on for $10 \mathrm{sec}$. At the end of this period, shock was delivered to the real subject and a signal to feign shock reception given to the confederate. For a "one" trial, the appropriate light came on and stayed on for $10 \mathrm{sec}$ unless the subject pressed the button. The confederate never pressed. Shocks or a signal to feign shock reception were given in a predetermined order when the subject did not respond. Trials were run with a $15-\mathrm{sec}$ ITI. There were eight "both" trials (B) and 12 "one" trials (0) in the order BOO $\mathrm{BO} \mathrm{BOO}$, etc. At each ostensible receipt of shock, the confederate jerked his/her arm and exclaimed loudly ("OW"!). The confederate's exclamation was unusual because the participants had been enjoined against talking. Ostensibly this was because of the physiological recording; in fact, it was to control interaction.
The level of the shock setting was announced to the participants at the beginning and the midpoint of the experiment, when it was changed. At the conclusion of the experimental task, subjects completed the questionnaires in which they rated their anxiety, the unplesantness of the shock, the confederate and themselves. They were told to rate themselves the way they thought the confederate would rate them. Subjects were then debriefed. No subject apparently disbelieved the experimental deception.

\section{RESULTS AND DISCUSSION}

An analysis of variance was performed on the percentage helping data. The dependent measure was percentage of "one" trials on which the subject volunteered for shock. This analysis showed a significant effect for the sex of the confederate $(F=14.81 ; \mathrm{df}=1$; $\mathrm{p}<.01)$ and an effect that approached significance for shock level setting $(F=3.46 ; \mathrm{df}=1 ; \mathrm{p}<.10)$. There were no other effects which approached significance. Females were helped on a much higher percentage of trials than males (59.58\% vs. 17.92), and subjects volunteered for shock more often on trials when shock level was low than when it was high $(41.67 \%$ vs. 35.82$)$. These results differ from those of Gruder and Cook (1971), who observed only slightly lower helping levels for males than females. They are similar to results reported by Latané and Darley (1970). These authors observed that passers-by were more likely to respond to a requests for aid ( 20 cents) from a female than from a male. They also tend to confirm the results of the Schaps (1972) and Schopler and Bateson (1965) studies, which showed higher helping levels when the cost of helping was low than when it was high.

The questionnaire ratings were made on six-point scales (0-5). These results were analyzed separately. The ratings of shock unpleasantness provided a check on the dependency manipulation. They showed that subjects perceived the confederate as receiving a much more unpleasant shock than they themselves received (4.2 vs. 2.35) $(\mathrm{F}=24.67 ; \mathrm{df}=1 ; \mathrm{p}<.01)$. A separate analysis revealed that subjects tested with a female confederate rated their anxiety levels as higher than subjects tested with a male confederate $(2.39$ vs. 1.34$)(\mathrm{F}=5.48 ; \mathrm{df}=$ $1 ; \mathrm{p}<.05)$. Thus, the experimental situation was apparently perceived as more threatening by subjects paired with a female than by those paired with a male.

The analysis of subjects ratings of themselves (self) showed very few significant differences. Ratings of the confederate (other) however, produced a number of significant differences and also an apparent pattern of differences. The mean ratings of male and female confederates which differed significantly or approached significance are shown in Table 1.

As the table shows, males are seen as stronger, braver, more leaders, more dominant, more masculine, more competitive, more aggressive, more independent, and larger. The rating in relation to size is especially 
interesting, since all confederates were of approximately the same height and build.

The ratings seem to indicate that even when a male acts in a dependent way, he is not perceived as dependent. In fact, he is perceived as larger than a similarly sized female. In relation to dependence, a similar observation was made in the Schopler and Bateson (1965) study. Subjects in this experiment were asked to recall the confederate's dependence. Their recall of the female confederate's dependence was highly accurate, but recall for the male was inaccurate.

Generally, the ratings in the present study seem to follow cultural role prescriptions. The one exception would seem to be the rating of females as more cowardly. That is, if dependence is "out of role" for the male, as Gruder and Cook (1971) suggest, then it should be perceived as cowardly. If the male confederate is not perceived as dependent, however, then he is apparently not cowardly. Further, if he is not dependent, then there is also little or no reason to help him. What was apparently perceived was a cultural stereotype of male behavior or maleness. Males are not dependent, they are aggressive, masculine, dominant, and competitive. Thus, they are not cowardly or weak, or at least, not as cowardly or weak as women. This would seem to be an important observation in relation to dependency manipulations in helping studies. Similar circumstances are not perceived in the same way given the presence of different sexes in the role of beneficiary.

The appraisal of the female is equally as interesting. Although she is weak and cowardly, a follower, and submissive, she also is rated better and more honest; she is a woman and she is helped more. Weakness, cowardice, and submissiveness are apparently acceptable female characteristics in our society in these circumstances. The female and not the male is dependent and therefore she should be helped. This perhaps explains the higher anxiety levels shown by subjects paired with a female confederate. Her dependence apparently elicited a feeling of responsibility in the male subjects. Given the presence of the shock, this led to higher anxiety levels.

Whether women subjects would feel the same sense of responsibility toward a female confederate in the present circumstances seems open to question. Although both the Gruder and Cook (1971) and Schopler and Bateson (1965) results indicate that they should, neither of these studies included a penalty for helping as aversive as electric shock. The behavior of female subjects and their perceptions of both female and male confederates in the present situation should be measured.

\section{REFERENCES}

Berkowitz, L., \& Daniels, L. Responsibility and dependency. Journal of Abnormal and Social Psychology, 1963, 66, 429-436.

Gruder, C. L., \& Cook, T. D. Sex, dependency and helping. Journal of Personality and Social Psychology, 1971, 19, 290-294.

Latané, B.. \& Darley, J. M. The unresponsive bystander: Why doesn't he help? New York: Appleton-Century-Crofts, 1970.

Schaps, E. Cost, dependency and helping. Journal of Personality and Social Psychology, 1972, 21, 74-78.

Schopler, J., \& Bateson, N. The power of dependence. Journal of Personality and Social Psy chology, 1965, 2, 247-254.

(Received for publication January 10, 1975.) 